\title{
A study on ranking the effects of transformational leadership style on organizational agility and
} mediating role of organizational creativity

\author{
Seidmehdi Veiseh ${ }^{\mathrm{a}}$, Ardshir shiri ${ }^{\mathrm{a}}$ and Neeman Eghbali ${ }^{\mathrm{b}}$
}

${ }^{a}$ Department of Management, University of Ilam, Ilam, Iran

${ }^{b}$ Master in Business Administration, Science and Research Branch, Islamic Azad University, Ilam, Iran

\section{H R O N I C L E}

Article history:

Received March 202014

Accepted 28 July 2014

Available online

August 32014

Keywords:

Transformational leadership

Organizational agility

Organizational creativity

Ilam Gas Refinery

\begin{abstract}
A B S T R A C T
The purpose of this study was to investigate the effects of the components of transformational leadership style on organizational agility and mediating role of organizational creativity in Ilam Gas Refinery located in province of Ilam, Iran. The method of the present study was descriptive and correlational-structural equation modeling. The population of this research included all 400 workers of Ilam gas refinery and the study chose a sample of 196 employees. The questionnaire was standardized using Cronbach's alpha; the obtained reliability was 0.90 , which indicated the reliability of the questionnaire. At the end, the data was analyzed by LISREL software and structural equation modeling analysis was conducted. The findings showed that transformational leadership style had an effect on organizational agility. In addition, organizational creativity maintained a mediator role on influencing the transformational leadership on organizational agility. The four dimensions of transformational leadership, hopeful influence, inspirational motivation, intellectual encouragement as well as personal considerations also influenced on the agility of organizations.
\end{abstract}

\section{Introduction}

Today's organizations face issues such as rapid, instant, and unpredictable changes, and special orders and expectance of a high level of personalized customer service. Hence, there is not an easy path to survive, to follow good customer retention, and to transit from traditional organizations to elite organizations. For this purpose, there have been many changes in attitudes, goals, work practices, and management of organizations such as agility. In fact, agility is a new paradigm in engineering competing firms (Jafarnejad \& Shahaee, 2006). Sharifi and Zhang (1999) defined organizational agility as the capability of each organization to sense, to understand, and to predict changes in the work environment. Such an organization must be able to detect changes in the environment and views them as agents of growth and prosperity. Agility of an organization is the overall ability to understand environmental change and to respond quickly and effectively. These changes might be changed in

*Corresponding author.

E-mail addresses: Amir7912000@yahoo.com (N. Eghbali) 
business environment, technological changes, or changing of customer needs. The word "agile" describes the speed and strength of responding in facing the internal and external events (Khoshsima, 2007). The agile organization is designed to understand and to predict changes in the business environment. Nowadays we need to teach people to be creative, so we move towards a prosperous society. The ever-increasing growth of information has led people to have the experience and knowledge that others do not have the chance to learn, so activating the information, knowledge, and experience of individuals is one of the secrets of success in today's world. No one is capable of understanding the real amount of information stored in the corners of one's mind. This information is activated when a strong motivation causes the information to release. In this stage, human beings care about each other's destiny and thrive for each other's growth; at the end, a stream of information and knowledge flows amongst them, which would be the basis of innovation and creativity. Considering all these facts overall, the current study seeks to answer the fundamental question of whether or not the relationship between transformational leadership style and organizational agility is a meaningful relationship and whether or not in this relationship organizational creativity has a mediator role.

\section{Review of literature}

\subsection{Transformative leadership}

Significant changes in the business environment are the main features of the present century (Singh, 2005). Rapidly changing environment, industry, customers, clients, competitors, partners, products, and services are all the forces that influence any firm and create a necessity to encourage excellence (Singh, 2008). However, understanding the environment, recognizing and understanding the changes, and identifying the threats, limitations, and utilities are essential for modern organizations (Taghavi Ghareh Bolagh, 2010). Management is not possible through traditional management approaches (Lloréns Montes, 2005). Extensive changes and globalization in today's world needs a new and different leadership style, where the optimum use of human and material resources and assets helps organization achieve its goals and develop the capacities. The leaders, who create new perspectives, prepare and develop conception, and prepare their staff by encouraging them and inspiring commitment and responsibility, utilize the factors and elements in a way that both guarantees the organization's survival and growth. These leaders have the ability to operate effectively in a complex and risky situation, and make themselves and their employees prepared to take appropriate action when facing challenges and potential opportunities. Leaders who prepare the condition for their employees to participate voluntarily and thrive through being responsible and using their imagination and ideas; and eventually lead the organizations to being learning organizations. Such leaders are called transformational leadership. Transformational leadership is one the newest styles of leadership which has become into the spotlight (Mortazavi \& Nazemi, 2006). This style of leadership has many advantages such as organizational learning.

\subsection{Organizational Creativity}

Having an innate talent and individual creativity is an important foundation for a creative society. Improving individuals' creativity is possible through having a transformational and changeable culture and tradition, establishing high education institutes and enhancing their quality, and paying attention to the society's values, which leads to improvement and creativity of human resources (Yousef, 2009). Most organizations attempt to hire new employees who have the capability to adapt to unanticipated changes and interact effectively with various individuals. However, recent advances has led organizations' leaders to encourage self-promotion and creativity in their employees, and help them to overcome their weaknesses and focus on nurturing the qualities of a good employee instead of hiring individuals with such qualities (Moss et al., 2009). Creativity is based on human's will, in fact, our creativity is the power to choose and to make decisions (Pirkhaefi, 2000). Creativity is an essential part in all fields of life and mental and physical health of human beings. People will be devastated if they get caught up in repetitive and mechanical routines. This is one of the threats to 
civilization. Most of the destroyed civilizations are not gone only because of external threats, but mainly due to decline of creativity and getting caught up in repetition. Today, organizations are successful which can satisfy the human force's needs and enhance creativity and innovation in employees and make them to thrive and improve the organization's productivity in this way (Mirkamaly \& Khorshidi, 2008). All organizations are in need of new innovative ideas and concepts. New ideas and innovative concepts are like reviving forces in an organization, which saves them from being doomed. Nowadays we have to improve creativity and innovation in organizations to survive, develop, and maintain the present status, and prevent its stagnation and destruction (Alvani, 2008).

\subsection{Organization Agility}

With increasing the changes in the business environment and becoming more competitive, organizations have to produce a system, which could help them respond to all customers' requirements. Customers always need more and more varied products and tend to use them to get them with more speed (Carlson \& Yao, 2008). Today's organizations are working in an environment of rapid change, which requires them to have adaptable strategies. In fact, the issue of how organizations can succeed in a dynamic and unpredictable environment is recognized as the most important challenge in today's world. However, different solutions such as on time production, reengineering, virtual organizations, and networking are introduced, but the most popular is the agile navigation. In such an environment, agility is becoming an important capability, which has a significant effect on organizational performance (Ravichandran, 2007). Agile production can be defined as the survival and development in a competitive environment whose main characteristic is change and instability, which reacts quickly and effectively to the changing markets according to the customers' needs (Sterling, 2008).

\section{Review of previous research}

Mohammadi and Amiri (2012) presented an interpretive structural modeling to achieve agility through IT in manufacturing organizations and reported the willingness and commitment of senior managers, organizational atmosphere, and alignment of strategic planning with IT planning were the influential factor in achieving agility through IT. Mazloomi et al. (2014) studied the relationship between transformational leadership and organizational creativity and innovation of the private insurance companies. They reported that there was a relationship between transformational leadership and organizational innovation, and organizational creativity is a mediator variable. Beiginia et al. (2011) studied the effect of adoption of information technology on organizational agility and reported that the adoption of information technology (using real data) had a significant effect on organizational agility. Khan et al. (2009) reported that the size of the organizations maintained a significant mediating role in the relationship between all the aspects of transformational leadership, mental persuasion, inspirational motivation, individualized consideration, and charisma, and organizational innovation. The results also showed a positive effect of transformational leadership on organizational innovation.

\section{Research hypotheses}

\subsection{Main research hypotheses}

1. Transformational leadership style has an effect on organizational agility in Ilam Gas Refinery.

2. In the effect of transformational leadership on organizational agility in Ilam Gas Refinery, organizational creativity has a mediator role.

\subsection{Sub-hypotheses}

1. Hopeful influence style has an effect on organizational agility in Ilam Gas Refinery. 
2. Inspirational motivation has an effect on organizational agility in Ilam Gas Refinery.

3. Intellectual encouragement has an effect on organizational agility in Ilam Gas Refinery.

4. Personal observations has an effect on organizational agility in Ilam Gas Refinery.

\section{Conceptual model}

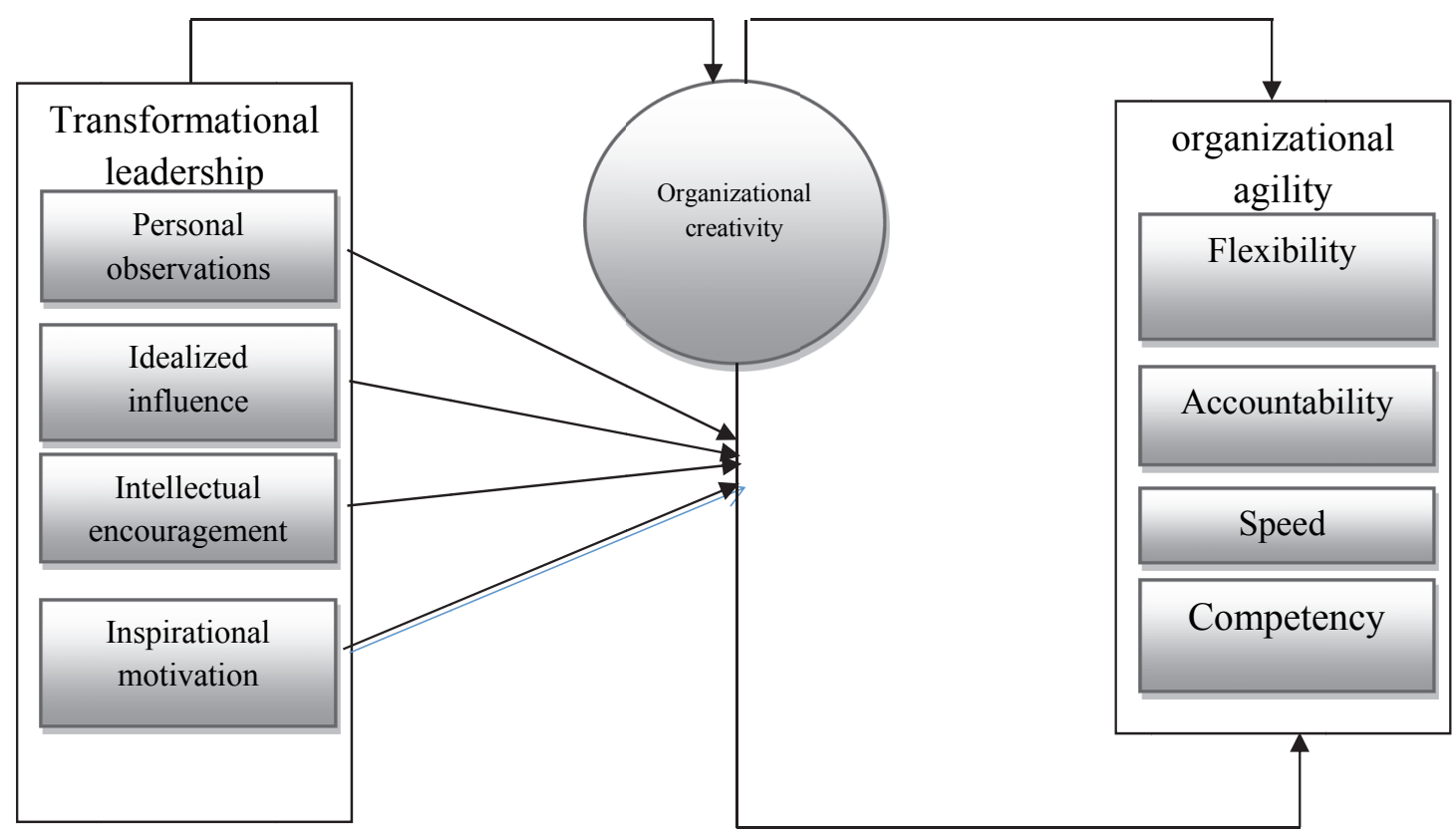

Fig. 1. The structure of the proposed model

\section{Research Methodology}

This study is quantitative and tries to reach some applied goals. In addition, the method used in this research is descriptive-survey. The initial questionnaire has been prepared based on literature and previous studies. The questionnaire included 32 questions, 4 items were related to demographic questions, 18 items were related to the transformational leadership, 10 items related to organizational creativity and 15 questions related to aspects of organizational agility. The population included all the staff of Ilam Gas Refinery which included 400 people. The estimated sample size using Morgan Table was 196.

Table 1

Cronbach's alpha coefficient for variables of the study

\begin{tabular}{|c|c|c|c|}
\hline Variable & dimensions & number of Items & Cronbach's alpha \\
\hline \multirow{4}{*}{ Transformational leadership } & Personal observations. & Q1- Q5 & $89 \%$ \\
\hline & hopeful influence & Q6-Q10 & $91 \%$ \\
\hline & Mental encouragement & Q11-Q14 & $92 \%$ \\
\hline & Inspirational motivation & Q15-Q18 & $88 \%$ \\
\hline Organizational relativity & - & Q19-Q28 & $84 \%$ \\
\hline \multirow{4}{*}{ Organizational agility } & Flexibility & Q29-Q33 & $86 \%$ \\
\hline & Accountability & Q34-Q37 & $87 \%$ \\
\hline & Speed & Q38-Q40 & $90 \%$ \\
\hline & Competency & Q41-Q43 & $91 \%$ \\
\hline Total & & & $90 \%$ \\
\hline
\end{tabular}


Validity and reliability of the questionnaire was tested. In this study, content validity, and factorial validity of the questionnaire were examined. The content validity of the questionnaire was tested by elites and experts of the field. Also using Confirmatory Factor Analysis, validity of each of these structures was calculated. Cronbach's alpha was used to confirm the reliability. The results are presented in Table 1, indicating that all aspects of reliability have an acceptable level (greater than $0.7)$.

\section{Findings}

This section explores the relationships of the research model. First, using structural equation techniques and at the end the LISREL method of data is used to analyze the data. One of the most important indicators used to evaluate the fitness of model is goodness of fit index or GFI, which is a measure of the relative amount of variances and co-variances and is commonly justified by the model. The closer GFI is to 1 , the better fitting the model has with the data. In addition, if the square root of the variance of the estimated error of approximation (RMSEA) is less than .05, it is acceptable.

\section{Table 2}

Results of confirmatory factor analysis for validity of the measurement model

\begin{tabular}{ccccc}
\hline indexes & Acceptable level & Estimated coefficients of model 1 & Estimated coefficients of model 2 & Result \\
\hline GFI & Greater than .9 & 0.95 & 0.93 & Good fit \\
AGFI & Greater than .9 & 0.98 & 0.99 & Good fit \\
RMR & Better if closer to zero & 0.09 & 0.11 & Good fit \\
NFI & Greater than .9 & 0.99 & 0.96 & Good fit \\
IFI & Greater than .9 & 0.94 & 0.93 & Good fit \\
\hline
\end{tabular}

For all latent variables (constructs of the model), factor analysis was performed and the values of the indexes were indicating that the validity of the measurement model was acceptable. Table 3 summarizes the results of the confirmatory factor analysis of these indexes.

\section{Table 3}

Summary of the research sub-hypotheses and test results

\begin{tabular}{lccc}
\hline Hypothesis & $\beta$ & T-Value & Evaluation \\
\hline There is a significant relationship between transformational leadership style and organizational agility. & .75 & 6.29 & confirmed \\
There is a significant relationship between personal considerations and organizational agility. & .70 & 9.07 & confirmed \\
There is a significant relationship between idealized influence and organizational agility. & .75 & 7.12 & confirmed \\
There is a significant relationship between mental encouragement and organizational agility. & .81 & 8.58 & confirmed \\
There is a significant relationship between inspirational motivation and organizational agility. & .86 & 10.12 & confirmed \\
There is a significant relationship between taking risks and organizational creativity. & .81 & 41.5 & confirmed \\
\hline
\end{tabular}

Based on a rule of thumb, the hypothesized model, the fitted model, is obtained when the coefficients calculated in Table 3 are in the acceptable range. If the calculated coefficients are not within the acceptable range, that index is poorly fitted.

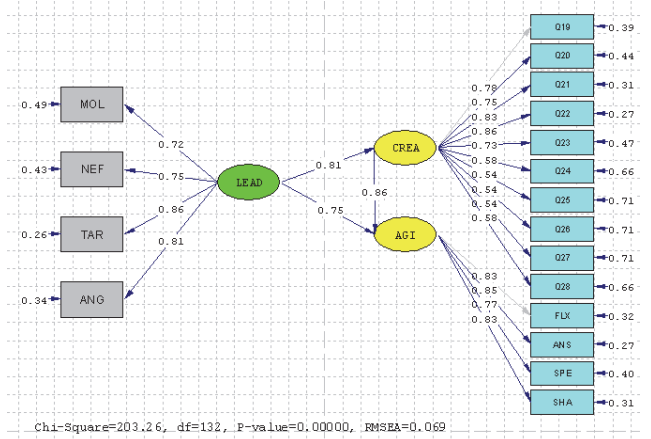

The results of standard coefficients

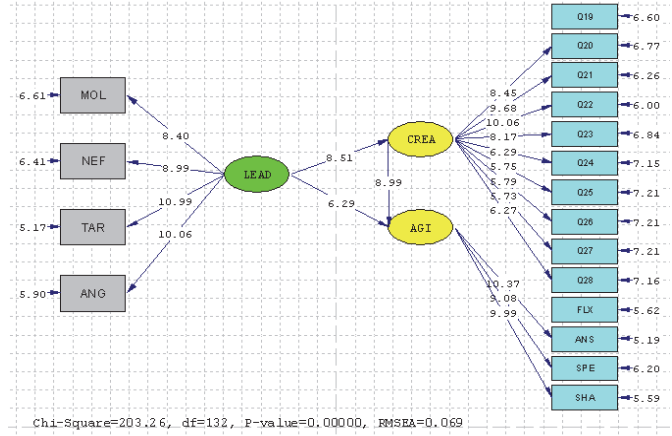

The results of $\mathrm{t}$-value

Fig. 2. The summary of the implementation of structural equation modeling 
The comparison of the calculated coefficients with the acceptable level reveals that the fitness indexes of the model are good. To rank and to decide about the level of importance of the different dimensions of transformational leadership, Freedman test has been used and the results are summarized in Table 4.

Table 4

Ranking and importance of the dimensions of transformational leadership

\begin{tabular}{ccc}
\hline Variable & mean & rank \\
\hline Idealized influence & 3.27 & 3 \\
Inspirational motivation & 4.05 & 1 \\
Mental encouragement & 3.64 & 2 \\
Personal considerations & 2.95 & 4 \\
\hline
\end{tabular}

According to the results of Table 4, inspirational motivation maintains the highest effect on the organizational agility followed by mental encouragement, idealized influence and personal consideration.

\section{Conclusion}

The primary objective of the present study was to rank the components of transformational leadership style on organizational agility and mediating role of organizational creativity in Ilam Gas Refinery. To conduct this research, six hypotheses were examined. Dimensions of transformational leadership style and organizational creativity were considered as factors influencing organizational agility. According to the testing of the hypotheses of the study, there was a significant relationship between the dimensions of transformational leadership style and organizational agility. The results of the survey are consistent with the obtained results by Khan et al. (2009), etc.

Considering the fact that transformational leadership style has an influence on organizational creativity, and organizational creativity has an influence on organizational agility, thus organizational creativity in the influence of transformational leadership style has a mediating role on the organizational agility. Results of this hypothesis is consistent with the results of Mohammadi and Amiri (2013) and Sharifirad et al. (2013).

\section{Suggestions}

1. Encouraging strategies have an impact on improving the organizational creativity. Improving the organizational creativity, like any other behavior of the individuals needs encouragement. The organizations can facilitate the improving of the organizational creativity by creating an organized system for rewarding the staff. The managers of organizations should practice encouragement strategies and try to increase organizational creativity in their employees.

2. Organizations should reform their structure and move towards un-focusing and let the employees know the decisions that they make and give them enough authority to do some organizational affairs. This makes the organizations more agile. Expanding the informal mechanisms such as cooperation value is a pivotal element for enhancing cognitive cultural intelligence in the workplace.

3. Managers and the staff should try to build trust in the work environment; because it leads to organizational creativity, and consequently helps the progress of performance and productivity of the organization. Staff should be able to cooperate more in the organization's activities and a communicating based on mutual forms in the work environment should be formed.

4. Attempts should be made to make an environment that everybody can cooperate actively and present their ideas freely; and factors such as challenging communications to improve the 
organizational issues, innovation, and freely experiencing one's opinion should be rewarded. Transformational leadership styles should be used to make a consultative atmosphere.

5. Organizations need extra-institutional cooperation to achieve organizational agility and to produce the products, which interests all members of the organization. To optimize agility, survival of the firms, and virtual producers should create a business cooperation environment and broader levels (regional and local) for the preparation and provision of advanced infrastructure requires virtual network participation of the partner organizations. These organizations have the ability to understand and take advantage of the rapidly changing opportunities in the form of a collaborative agent. These organizations can use other's competencies. In fact, they re-define the real nature of business in the form an agency.

\section{References}

Alvani, SM. (2008). Public Management. Tehran, Ney publication.

Beiginia, A., Alwan, S.M., \& Gulshan, A. (2011). Effect of adoption of information technology on organizational agility (Case Study: National Petrochemical Company). Daneshvar Journal, 50, 99113.

Carlson, J. G., \& Yao, A. C. (2008). Simulating an agile, synchronized manufacturing system. International Journal of Production Economics, 112(2), 714-722.

Jafarnejad, M., Shahabi, B. (2006). Organizational agility and agile manufacturing. Tehran, gentle book publishing firm. 134-147.

Khan, R., Rehman, A. U., \& Fatima, A. (2009). Transformational leadership and organizational innovation: Moderated by organizational size. African Journal of Business Management, 3(11), 678-684.

Khoshsima, G.R. (2007). Introduction to enterprise agility. Compass Magazine, 134, 87-99.

Mazlomi, N., Nasehyfar, V., \& Ehsanfar, G. (2014). The relationship between transformational leadership and organizational creativity and innovation of the private insurance companies. Insurance Journal, 1(109), 33 - 56.

Mirkamaly, S.M., \& Khorshidi, A. (2008). Methods of creativity in education, Tehran, Iran.

Mortazavi, S. \& Nazemi, Sh. (2006). Examination the relationship between emotional intelligence \& leadership style. The Modares Journal of Management, 92, [in Persian].

Lloréns Montes, F. J., Ruiz Moreno, A., \& García Morales, V. (2005). Influence of support leadership and teamwork cohesion on organizational learning, innovation and performance: an empirical examination. Technovation, 25(10), 1159-1172.

Moss, S. A., Dowling, N., \& Callanan, J. (2009). Towards an integrated model of leadership and self regulation. The Leadership Quarterly, 20(2), 162-176.

Mohammadi, A., \& Amiri, Y. (2012). Provide interpretive structural modeling to achieve agility through IT in the organization of production. Journal of Management, 13, 115 -134.

Noruzy, A., Dalfard, V. M., Azhdari, B., Nazari-Shirkouhi, S., \& Rezazadeh, A. (2013). Relations between transformational leadership, organizational learning, knowledge management, organizational innovation, and organizational performance: an empirical investigation of manufacturing firms. The International Journal of Advanced Manufacturing Technology, 64(5-8), 1073-1085.

Pirkhaefi, A., (2000). Developing Creativity Intellectual Development of Children and Adolescents. Tehran, Center for Distance Learning.

Ravichandran, T. (2007). IT Competencies. Innovation Capacity and Organizational Agility: Performance Impact and the Moderating Effects of Environmental Characteristics-Lally School of Management \& Technology Rensselaer Polytechnic Institute-Submitted to CIST, INFORMS.

Sharifi, H., \& Zhang, Z. (1999). A methodology for achieving agility in manufacturing organisations: An introduction. International Journal of Production Economics, 62(1), 7-22. 
Sharifirad, M. S. (2013). Transformational leadership, innovative work behavior, and employee wellbeing. Global Business Perspectives, 1(3), 198-225.

Singh, K. (2008). Relationship between learning organization and transformational leadership: banking organizations in India. International Journal of Business and Management Science, 1(1), 97-111.

Singh, K. (2005). Organization change and development, New Delhi: excel books publisher.

Sterling, J. (2008). Organizational Agility-The Association for Laboratory Automation. Sage.

Taghavi Ghareh Bolagh, H. (2010). Examination of the relationship between personality and transformational leadership among 19 regions of administrators of the ministry of education in Tehran, M.A dissertation of Tehran university (in Persian).

Yusuf, S. (2009). From creativity to innovation. Technology in Society, 31(1), 1-8. 